\title{
Occupational hazard prevention and control in a quarry environment: exposure to airborne dust
}

\author{
G. Alfaro Degan, D. Lippiello \& M. Pinzari \\ Department of Engineering, ROMA TRE University, Italy
}

\begin{abstract}
Dust emissions may be considered among the most critical hazards to be found in quarries due to the design and nature of this working environment. Not only does dust impair the quality of the air from an environmental perspective, but it also impinges on the health and safety of workers. Those responsible for the quarry must demonstrate their compliance with industry standards and legal regulations, and are thereby required to implement several dust mitigation techniques in order to comply with air quality standards and pollutant emission limits. The aim of this paper is firstly to evaluate how quarry workers are affected by the mitigation techniques designed to reduce the impact of dust emissions on the environment. Secondly, an attempt is made to determine which of the proposed strategies is the most effective both in reducing emissions and in reducing the workers' exposure, and thus defining a suitable strategy on which to focus. The analysis is carried out in four consecutive phases. In the first, the $\mathrm{PM}_{10}$ concentration is sampled and the daily exposure of workers to the respirable fraction of airborne dust is measured. In the second, mitigation techniques, are applied to the main sources of dust according to the technical guidelines stipulated in international standards and norms. In the third phase, the pollutant concentration $\left(\mathrm{PM}_{10}\right)$ is resampled at various points throughout the quarry plant and a further sampling campaign is carried out with personal samplers to assess workers' exposure and their daily dose. A comparison of these two sets of values allows both the effectiveness of the applied dust mitigation techniques and the influence of $\mathrm{PM}_{10}$ concentration on the respirable fraction of airborne dust to be quantified. In the final phase, personal samplers are used in order to test the Functional Analysis Space Technique risk assessment procedure in forecasting the daily dose.
\end{abstract}

Keywords: PM 10 , respirable dust, workers' exposure, quarries, FAST. 


\section{Introduction}

The emission of airborne particulates $\left(\mathrm{PM}_{10}\right)$ constitutes an important aspect of the problems regarding health and safety management and also of environment issues related to quarry activities. They may cause adverse effects in the area surrounding the extractive site especially concerning the quality of the air, but also in regard to the workers who operate the plant machinery.

In order to safeguard the health of quarry workers there is legislation in force nationally (Legislative Decree 81/08) and internationally (BS OHSAS 18001:2007), both of which take a similar approach [1]. The quarry responsible is required to act according to common criteria, and must, wherever possible, eliminate exposure risks from pathogen agents, including airborne pollutants. Should elimination of such risks prove impossible, they must be reduced to a minimum, giving priority to those measures which are aimed at reducing the risk at its source. Nevertheless, the airborne particulate pollutant emitted into the atmosphere must be limited in accordance with Legislative Decree 152/06, through the adoption of a series of specific technical measures at each single source. The quarry responsible must also guarantee that same the level of safety has been maintained, by periodically measuring both the amount of occupational exposure and the emissions into the environment.

This paper presents a case study in the extractive industry sector in the Lazio region of Italy in order to evaluate the effect the containment measures and the measures to reduce emissions carried out at source have on the exposure of the quarry workers. The paper also aims to investigate any possible correlation between the different types of measures and the exposure levels; and finally to make a tentative prediction of the occupational exposure to the respirable particulate matter from data of its concentration in the environment.

With regard to the literature, the aspects relating to the containment of emissions have generated a certain interest in the scientific community ever since the first attempts were made to analyse the problem of airborne pollution at extractive sites [2], in the form of propagation mechanisms and mathematical modelling of the diffusion phenomena [3]. Numerous authors have focused on monitoring emission levels with respect to the main sources in quarries, concentrating especially on unpaved roads used by site machinery and vehicles [5-7], drilling and cutting rock, and work on the quarry face [8,9], as well as meteorological aspects, and techniques of measurement of particulate emissions $[10,11]$. Much literature may be found in relation to the extractive industry about the evaluation of worker exposure to airborne particulates, especially regarding respirable crystalline silica $[12,13]$, but also studies concerning inert dust in quarries $[14,15]$ as well as those aimed at evaluating the adverse effects of exposure to airborne particulates on workers' health [16]. In this framework, much in-depth research has been conducted with regard to mitigation and control of the concentration of airborne particulates especially in relation to the environment [17, 18], whereas there would appear to be lack of research regarding the effectiveness of containment measures on the daily dose absorbed by workers. 


\section{Materials and methods}

The research was carried out in a quarry which is located near Rome, Italy. The quarry produces basalt granules and the hazard analysed was inert airborne dust derived from basalt rock.

The analysis procedure was subdivided into four distinctive phases.

Firstly, a series of measurements was carried out to determine both the daily dose of the respirable fraction of airborne dust to which the machinery operators were exposed and the relative content of environmental $\mathrm{PM}_{10}$ present in the atmosphere in specific locations on site. This initial phase allowed the starting conditions to be evaluated. Only after this phase had been completed were the containment measures implemented, as described in detail below. After modifying the plant, both the daily dose of the respirable fraction of airborne dust and the relative content of environmental $\mathrm{PM}_{10}$ were measured again. The monitoring stage of the study was then completed by conducting a comparative analysis. The Functional Analysis Space Technique (FAST) methodology, [19], was used to test for correlations between the values obtained before and after the preventative measures had been carried out, and also used to attempt to predict the occupational daily dose of respirable airborne dust from $\mathrm{PM}_{10}$ concentration data.

The entire monitoring programme lasted two years from spring (MarchApril) 2012 to spring 2014. The instrumentation utilised measured both the environmental $\mathrm{PM}_{10}$ concentration and the daily dose of the respirable fraction of airborne dust gravimetrically. The $\mathrm{PM}_{10}$ concentration was measured using a TCR Tecora Bravo Plus M sampler with a specialized sampling head which conforms to the UNI EN 12341 specifications. The particulate was collected on cellulose nitrate filters of $47 \mathrm{~mm}$ in diameter. Gravimetric measurements were then carried out on the filters both before and after sampling. This analysis was conducted at the Mechanical Engineering Department of Roma 3 University by means of an analytical balance (Exacta series ABT 120-5 DM) with a sensitivity of five decimal places. Before carrying out the weighing operations the filters were prepared in a drier so as to reduce any error due to the hygroscopy of the instrumentation or filters themselves. Each value was determined on the basis of three independent but consecutive weightings. With regard to the reliability of the measurements, the effects of experimental uncertainty were considered to be linked to two factors: firstly in connection with determining the deposited mass and secondly regarding the uncertainty due to the volume of air captured in the sample. The first aspect was quantified through blank filter analysis, whereas the second was quantified following the calibration of the air inlet sampling pumps by means of a bubble primary flow calibrator accredited by the United Kingdom Accreditation Service (UKAS) and calibrated both for high and low flow rates and the associated random error (within $\pm 1 \%$ error). The combination of the two effects cited above allows the total uncertainty associated with the measurement to be estimated within two standard deviations. Personal exposure was measured concurrently with the environmental $\mathrm{PM}_{10}$ concentration by means of a personal sampler (aspirator SKC model 224 PCEX8) featuring a cyclone preselector with 
a flow stabiliser and filter cassettes, and which conforms to UNI EN 481 (1994) and UNI EN 482 (1998) specifications. The measurement of the respirable dose absorbed by the subject worker was carried out using the same weighing method as used for the environmental $\mathrm{PM}_{10}$ measurements.

\subsection{Location of study}

The measurement campaign was carried out in a basalt granule quarry in the Lazio region of Italy. Basalt is extracted from the rock face using single row blasting. The quarried material is then loaded and transported by dumper truck to the processing yard where it is crushed and selected. In the plant itself the material is then transported by means of conveyor belts connecting the various plant stations described below. The instruments which indicate the environmental airborne dust $\left(\mathrm{PM}_{10}\right)$ content were located in four working areas (or functional areas) that are: I - Quarry face area; II - Loading, unloading and manoeuvring area; III - Tertiary crushing area; IV - Primary crushing area.

There were 9 workers responsible for the plant operation who were subdivided into four groups corresponding to the different natures of their tasks.
A: Workers responsible for the quarry face and blasting operations ( 3 people);
B: Workers responsible for the transportation or loading of material (2 people);
C: Workers responsible for the tertiary crusher (2 people);
D: Workers responsible for the primary crusher (2 people).

\subsection{Preventative measures}

In order to carry out the preventative measures, firstly the sources of dust emission were identified, then appropriate measures were then taken according to the nature of each specific type of emission as shown below. The sources were classified into three general categories [20]:

1) Sources due to the production and processing of quarried material;

2) Sources due to transporting, loading and unloading quarried material;

3) Sources due to stockpiling quarried material.

\subsubsection{Material production and processing}

Production and processing refers to any activities involving cutting, drilling or crushing the material in question which generate airborne particulate. In such cases every attempt is made to enclose the source and, as this method cannot be carried out hermetically, to minimise the emission of dust into the air by employing a fog dust suppression system. The primary crusher and the cone crushers are therefore covered by means of welding sheet-metal screens onto the body of the machinery (see Figure 1(a)).

The material entering the various plants should also be kept sufficiently damp by installing a wetting system (Figure 1(b)).

Enclosing the processing plants also allows the particulate emissions to be channelled into special chimneys fitted with nozzles which spray the dust. This abatement system has the capacity to discharge $1.6610^{-4} \mathrm{~m}^{3} / \mathrm{s}$ of water at a 


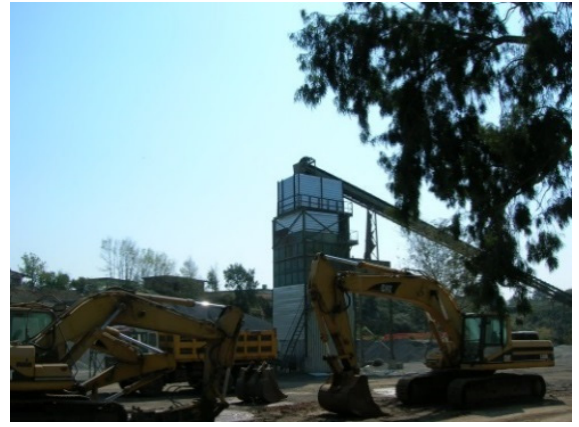

(a)

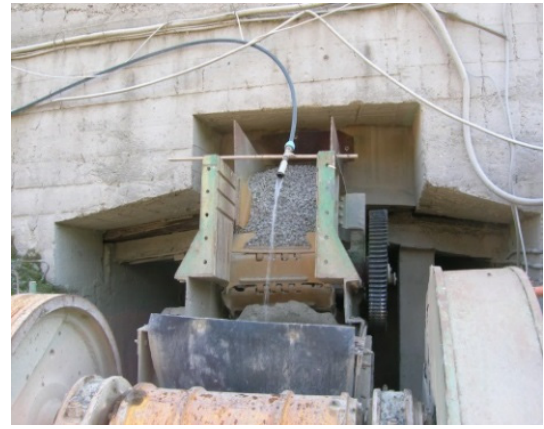

(b)

Figure 1: Some details of preventative measures.

working pressure of $510^{5} \mathrm{~Pa}$. The chimney height was greater than the height of the plant structure in all cases, with the exception of the chimney of the secondary cone crusher, which was lowered due to issues regarding the stability of the plant structure but which was more than ten metres above floor level in any event.

\subsubsection{Transporting, loading and unloading}

Transporting, loading and unloading regards any activity involving the transport or movement of the material in question. The procedure in these cases is wherever possible to enclose the material (e.g., by means of covering the material by tarpaulins while it is being hauled by vehicles). However, should this prove impractical, impossible or only achievable in part, the material should be partially covered and have a wetting system installed at the emission points. For instance the second option should be employed where material is transported via conveyer belts. In this case the belt should be enclosed by a covering and the transfer point should have a spray system installed.

With regard to loading and unloading operations, the attention is focused on limiting the speed of the material during these activities by means of installing deflectors as well as reducing drop heights to a minimum. The measures to mitigate the effect of vehicles raising dust clouds whilst in motion are to limit vehicle speed to $30 \mathrm{~km} / \mathrm{h}$ and to install a capillary wet dust suppression system throughout the quarry road network. As a consequence of the recorded frequency of transit (five vehicles per hour) it was deemed necessary to employ a wet dust suppression method which covered the entire yard surface with $510^{-4} \mathrm{~m}^{3} / \mathrm{m}^{2}$ of water.

\subsubsection{Stockpiling}

The location of the mounds of quarried material should be determined by the nature of the material to be stockpiled. Particular attention must be paid to the position of stockpiles of the smallest size of aggregate in order to take advantage of any structures, embankments or natural topological features which 
could provide barriers or shelter from the wind so as to try to prevent air currents from lifting particulate into the atmosphere. All of the stockpiles were equipped with a spray system in order to keep the stockpiled material sufficiently damp.

\section{Results}

\subsection{First measurement campaign (ante operam)}

The first phase of the measurements was carried out to evaluate the concentration of airborne dust present before the preventative measures were implemented. To this end, the four functional areas were chosen as described in 2.1. Each of the four locations was monitored for a period of four hours on three separate, unrelated occasions over a period of twelve days. The aim was to ensure representative measurements and therefore they were carried out during a period in which the plant machinery was fully functioning at its maximum capacity (i.e. under the heaviest normal workload) and in time windows which ensured values which were representative of normal emissions and of any variations in those emissions. The results obtained are the mean airborne pollutant $\left(\mathrm{PM}_{10}\right)$ concentrations (expressed in $\mu \mathrm{g} / \mathrm{m}^{3}$ ) during the observation period and are summarised in table 1 below.

Table 1: $\quad$ Ante operam data of $\mathrm{PM}_{10}$ concentration expressed in $\mu \mathrm{g} / \mathrm{m}^{3}$.

\begin{tabular}{|c|c|c|c|c|c|}
\hline Location & Campaign I & Campaign II & Campaign III & Mean & $\begin{array}{c}\text { Std. } \\
\text { Deviation }\end{array}$ \\
\hline I & 14250 & 12960 & 15730 & 14313 & 1131 \\
\hline II & 10920 & 9870 & 11350 & 10713 & 621.7 \\
\hline III & 17230 & 18290 & 13270 & 16263 & 2160 \\
\hline IV & 9720 & 8990 & 10150 & 9620 & 478 \\
\hline
\end{tabular}

With regard to the workers' exposure, three measurements were carried out for each type of task. Due to the fact that the workers who were responsible for the quarry face and blasting operations (members of group A) were not exposed continuously over time, these tasks were not monitored. The length of the monitoring time was that of a standard working day (07:30-16:30 excluding breaks). The values recorded are given in table 2 and are expressed in $\mu \mathrm{g} / \mathrm{m}^{3}$.

Table 2: Ante operam data of respirable daily dose for individual subjects.

\begin{tabular}{|c|c|c|c|c|c|}
\hline $\begin{array}{c}\text { Subject } \\
\text { from }\end{array}$ & Campaign I & Campaign II & Campaign III & Mean & $\begin{array}{c}\text { Std. } \\
\text { Deviation }\end{array}$ \\
\hline Group B & 1020 & 1360 & 1230 & 1203 & 171.5 \\
\hline Group C & 1380 & 1530 & 1400 & 1436 & 81.4 \\
\hline Group D & 930 & 1260 & 1180 & 1123 & 172.1 \\
\hline
\end{tabular}




\subsection{Second measurement campaign (post operam)}

The second measurement campaign was a repetition of the measurements in 3.1 recorded in the same way, in the same locations, under similar conditions. However, these measurements were conducted to evaluate the concentration of airborne dust present after the preventative measures had been implemented on the machinery and at the dust sources (i.e., carried out post operam). The results for the concentration of airborne pollutant and personal exposure are given below in table 3 and table 4 respectively and expressed in $\mu \mathrm{g} / \mathrm{m}^{3}$.

Table 3: Post operam data of $\mathrm{PM}_{10}$ concentration expressed in $\mu \mathrm{g} / \mathrm{m}^{3}$.

\begin{tabular}{|c|c|c|c|c|c|}
\hline Location & Campaign I & Campaign II & Campaign III & Mean & $\begin{array}{c}\text { Std. } \\
\text { Deviation }\end{array}$ \\
\hline I & 5720 & 4230 & 4870 & 4940 & 610 \\
\hline II & 4790 & 4030 & 3850 & 4223 & 407 \\
\hline III & 4390 & 5890 & 6310 & 5530 & 824 \\
\hline IV & 3670 & 3530 & 5010 & 4070 & 667 \\
\hline
\end{tabular}

Table 4: Post operam data of respirable daily dose for single subjects $\left[\mu \mathrm{g} / \mathrm{m}^{3}\right]$.

\begin{tabular}{|c|c|c|c|c|c|}
\hline $\begin{array}{c}\text { Subject } \\
\text { from group }\end{array}$ & Campaign I & Campaign II & Campaign III & Mean & $\begin{array}{c}\text { Std. } \\
\text { Deviation }\end{array}$ \\
\hline Group B & 840 & 1020 & 910 & 923 & 90.7 \\
\hline Group C & 1070 & 1190 & 1060 & 1106 & 72.3 \\
\hline Group D & 820 & 1010 & 1090 & 973 & 138.6 \\
\hline
\end{tabular}

\subsection{Comparison of the data}

The percentage of reduction in terms of daily dose absorbed for each worker as well as the percentage of reduction of the $\mathrm{PM}_{10}$ concentration for each functional area may be calculated from the results of the monitoring carried out before and after the modifications were made to the plant. The data are given below.

The measurements of $\mathrm{PM}_{10}$ concentration were taken from within the functional areas of the plant in which the constant presence of a worker is required to operate the machinery (with the exception of Area A, i.e., the quarry

Table 5: $\quad$ Reduction for each type of task expressed as a percentage of the ante operam daily dose.

\begin{tabular}{|l|c|c|c|c|}
\hline & $\begin{array}{c}\text { Subject } \\
\text { from A }\end{array}$ & $\begin{array}{c}\text { Subject } \\
\text { from B }\end{array}$ & $\begin{array}{c}\text { Subject from } \\
\text { C }\end{array}$ & $\begin{array}{c}\text { Subject from } \\
\text { D }\end{array}$ \\
\hline $\begin{array}{l}\text { Daily dose } \\
\text { reduction [\%] }\end{array}$ & - & $23.2 \%$ & $22.9 \%$ & $13.3 \%$ \\
\hline
\end{tabular}


Table 6: Reduction expressed as a percentage of the ante operam environmental $\mathrm{PM}_{10}$ for each functional area.

\begin{tabular}{|l|c|c|c|c|}
\hline & Area A & Area B & Area C & Area D \\
\hline $\begin{array}{l}\mathrm{PM}_{10} \text { concentration } \\
\text { reduction [\%] }\end{array}$ & $65.4 \%$ & $60.5 \%$ & $66.0 \%$ & $57.9 \%$ \\
\hline
\end{tabular}

face and blasting area). This fact gives rise to a further point for analysis. Since the daily absorbed dose is known for each of these workers, a correlation analysis is carried out between the values of the environmental $\mathrm{PM}_{10}$ and the dose absorbed by the worker in the same functional area. In table 7 below the composition of the air sample is given as a mean percentage for each functional area both before and after the preventative measures had been carried out on the plant.

Table 7: Comparison of the percentage of air samples.

\begin{tabular}{|l|c|c|}
\hline Functional area & $\mathrm{PM}_{10}[\%]$ & Respirable fraction [\%] \\
\hline Area B ante operam & 89.90 & 10.10 \\
\hline Area B post operam & 82.06 & 17.94 \\
\hline Area C ante operam & 91.88 & 8.12 \\
\hline Area C post operam & 83.32 & 16.68 \\
\hline Area D ante operam & 89.54 & 10.46 \\
\hline Area D post operam & 80.70 & 10.30 \\
\hline
\end{tabular}

Thus to summarise the outcome of the monitoring, a factor may be defined for each of the functional areas which characterises the composition of that specific air sample, as shown below:

$$
K_{n}=\frac{D_{n}}{C_{n}}
$$

where:

$\mathrm{K}_{\mathrm{n}}$ represents a factor which expresses the air sample composition of one specific functional area;

$D_{n}$ expresses the value of the post operam dose of the $\mathrm{i}^{\text {th }}$ functional area $\left[\mu \mathrm{g} / \mathrm{m}^{3}\right]$; $\mathrm{C}_{\mathrm{n}}$ is the value of the $\mathrm{PM}_{10}$ concentration of the same functional area $\left[\mu \mathrm{g} / \mathrm{m}^{3}\right]$.

These parameters assume the values given below for each functional area:

Table 8: $\quad$ Factors for the air sample for each individual functional area.

\begin{tabular}{|l|c|c|c|}
\hline & $\mathrm{K}_{\mathrm{b}}$ & $\mathrm{K}_{\mathrm{c}}$ & $\mathrm{K}_{\mathrm{d}}$ \\
\hline Ante operam & 0.11 & 0.08 & 0.11 \\
\hline Post operam & 0.21 & 0.20 & 0.23 \\
\hline
\end{tabular}




\section{Risk evaluation}

A proposal for the evaluation of the occupational daily dose absorbed by the workers from the $\mathrm{PM}_{10}$ concentration data is given below. Such an evaluation may be used as a forecast in that it allows the respirable dose to be estimated in advance, applying a time-space framework to the task to be introduced. The reliability of the procedure was tested, although limited to this particular case study, by measuring the resultant occupational dose.

\subsection{Functional Analysis Space Technique (FAST)}

The proposed instrument of analysis to predict the risk associated with a new task is the method of functional space analysis. The idea is based on characterising the two typical risk evaluation components separately: the danger and the target or worker. The danger is characterised by defining its intensity spatially, that is to say by defining the concentration of the airborne particulate inside the plant or, as in the case in question, inside functional areas. The worker and his or her presence is characterised by means of time-space discretization of the tasks carried out within the plant and is defined by the period of time spent within a determined functional area. Whenever the agent and the worker are both present (i.e., when the worker is exposed to the airborne hazard) the risk evaluation procedure may be followed as described below. The mean $\mathrm{PM}_{10}$ concentration values are indicated in the penultimate column of table 3 for each functional area. It is assumed that the composition of the air sample is constant (throughout the particular functional area and over time) in terms of both its $\mathrm{PM}_{10}$ concentration component and its respirable fraction of the particulate matter, according to the values from eqn (1), which are summarised in table 7. Lastly, given that the period of time a worker spends doing a 'new' task in a particular functional area is known, and considering the various contributory factors with respect to a standard working day (see table 9), the calculation of the dose which will be absorbed by worker $\mathrm{X}$ is carried out as follows:

Table 9: Period of time spent in each of the functional areas by worker X.

\begin{tabular}{|c|c|}
\hline Functional area & Time period [minutes] \\
\hline B & 180 \\
\hline C & 180 \\
\hline D & 120 \\
\hline
\end{tabular}

$$
D_{x}=\sum_{i=1}^{n} \frac{K_{i} C_{i} \Delta t}{T_{0}}
$$

where:

$D_{x}$ expresses the value of the dose relative to the worker performing task $\mathrm{X}$ and expressed in $\left[\mu \mathrm{g} / \mathrm{m}^{3}\right]$;

$\mathrm{K}_{\mathrm{i}}$ expresses the calibration factor for the $\mathrm{i}^{\text {th }}$ functional space [n];

$\mathrm{C}_{\mathrm{i}}$ expresses the value of the mean $\mathrm{PM}_{10}$ concentration relative to the $\mathrm{i}^{\text {th }}$ functional space $\left[\mu \mathrm{g} / \mathrm{m}^{3}\right]$; 
$\Delta t$ expresses the period of time spent in the $\mathrm{i}^{\text {th }}$ functional space [min];

$\mathrm{T}_{0}$ expresses the length of a standard working day equal to 480 minutes [min];

On its application the proposed method returns a dose of $1007.34 \mu \mathrm{g} / \mathrm{m}^{3}$.

\section{Discussion and conclusions}

It may be confirmed that the containment measures carried out to reduce particulate emissions produced the expected results with regard to the plant analysed and the data gathered in this case study. The mean reduction in the concentration of $\mathrm{PM}_{10}$ was recorded as being between $58 \%$ and $66 \%$ depending on the functional area. This reduction also determined a reduction in the occupational dose of the respirable particulate matter absorbed by workers carrying out tasks in the plant. It is interesting to note that even though the worker is in exactly the same functional area monitored for $\mathrm{PM}_{10}$, there appears to be a considerable reduction in the absorbed dose. For a given functional area the reduction recorded was between $13 \%$ and $23 \%$. These data may be explained in the light of the fact that the aim of implementing the containment measures was in fact the reduction of $\mathrm{PM}_{10}$ emission into the atmosphere and thus predictably the most immediate effect was a reduction in the concentration of this pollutant. Furthermore, it should also be noted that the conventional definition of 'respirable', as defined by EN UNI 481/94, is a cumulative lognormal distribution with a median value of equal to $4.25 \mu \mathrm{m}$. Even considering typical references from the literature regarding quarries [21] about the granulometric composition of airborne dust the data appears to be consistent with the state of the art. The containment measures adopted therefore appear to be more effective on the larger sized of the $\mathrm{PM}_{10}$ which, mass density being equal, also constitute the heaviest part and resulting in a considerable reduction in concentration. With regard to the respirable fraction and the smaller sized particles of the $\mathrm{PM}_{10}$, the reduction appears to be more complex, which is probably also due to the lesser effect of the gravimetric deposition.

From this finding regarding the change in the airborne particulate composition following the modifications implemented on the plant, an application of the functional space method is used to predict the dose absorbed by a worker. This example stems firstly from being able to access $\mathrm{PM}_{10}$ concentration data for the plant from the checks the quarry company are required to perform regularly to monitor the environment, but also from an attempt to reduce the number of personal samples which would otherwise need to be carried out on all of the workers. Besides, the opportunity of knowing the concentration to which a worker will be exposed in advance, albeit approximately, allows the employers to evaluate whether workers should be provided with protective equipment such as breathing masks or filters. Under the simplifications made that the $\mathrm{PM}_{10}$ concentration is constant in a given functional space and that its relationship with the respirable fraction is also constant at least within a given functional space, a prediction of the occupational dose for a given task was made. The result was then verified experimentally utilising a dosimeter, which recorded a value that was $9 \%$ greater than predicted. 


\section{References}

[1] Alfaro Degan G., Lippiello D., Pinzari M. (2009). Occupational health and safety management systems: comparison between BS OHSAS 18001: 2007 and Italian Decree 81/2008. WIT Transactions on Biomedicine and Health, Vol. 14, WIT Press, 2009, ISSN: 1743-3525, pp. 401-409, doi: 10.2495/EHR090391.

[2] Patrucco, M., Clerici, C. Problemi di inquinamento particolato nell'attività di cava: aspetti generali del controllo e della riduzione. Bollettino dell'Associazione mineraria subalpina, 9, pp. 123-131, 1986.

[3] Vella, J.A., Camilleri, R., 2005. Fine dust emissions from softstone quarrying in Malta. Xjenza. 10. pp. 47-54.

[4] McCain, J. D., Pyle, B. E., McCrillis, R. C., 1985. Comparative Study of Open Source Particulate Emission Measurement Techniques, in Proceedings of the 78th Air Pollution Control Association Annual Meeting, Detroit, MI.

[5] Abu-Allaban, M., Hamasha, S., Gertler, A. Road dust resuspension in the vicinity of limestone quarries in Jordan. Journal of the Air \& Waste Management Association, 56 (10), pp. 1440-1444, 2006.

[6] Piras, L., Dentoni, V., Massacci, G., Lowndes, I.S. Dust dispersion from haul roads in complex terrain: the case of a mineral reclamation site located in Sardinia. International Journal of mining reclamation and the environment, 28(5), pp. 323-341, 2014.

[7] Alfaro Degan, Lippiello D, Pinzari M. Total Suspended Particulate from mobile sources in an Italian opencast quarry: a proposal to improve US EPA ISC3 model. Advances in Safety, Reliability and Risk Management. Proceedings of Proceedings of the European Safety and Reliability Conference (ESREL). Ed: C. Berenguer, A. Grall, C. \& Guedes Soares, Taylor \& Francis Group: London, pp. 2984-2990, 2012.

[8] Cole, C. F., Fabrick, A.J. Surface Mine Pit Retention. Journal of the Air Pollution Control Association, 34, pp. 674-675, 1984.

[9] Organiscak, J.A., Page, S.J. Field assessment of control techniques and long-term dust variability for surface coal mine rock drills and bulldozers. International Journal of Surface Mining, Reclamation and Environment, 13, pp. 165-172, 1999.

[10] Alfaro Degan G., Di Bona G., Lippiello D., Pinzari M. PM $\mathrm{P}_{10}$ dispersion model in quarrying activities: a comparison of an ISC3 approach with a mono/multivariate geostatistical estimation. WIT Transactions on Ecology and the Environment, WIT Press, 2006, ISSN: 1743-3541, vol. 86, pp.111120, doi: 10.2495/AIR060121.

[11] Alfaro Degan G., Lippiello D., Pinzari M. Monitoring airborne dust in an Italian basalt quarry: comparison between sampling methods. In: WIT Transactions on Ecology and the Environment. WIT Press, 2013, ISSN: 1743-3541, vol. 174, pp. 75-84, doi: 10.2495/AIR130071.

[12] Lira, M., Rabbani, K.E., Barkokebas, J.B. et al. Risk evaluation and exposure control of mineral dust containing free crystalline silica: a study 
case at a quarry in the Recife Metropolitan Area. Work-A Journal of Prevention, Assessment \& Rehabilitation, 41 (1), pp. 3109-3116, 2012.

[13] Golbabaei, F., Barghi, M.A., Sakhaei, M. Evaluation of workers' exposure to total, respirable and silica dust and the related health symptoms in Senjedak stone quarry, Iran. Industrial Health, 42 (1), pp. 29-33, 2004.

[14] Bujak-Pietrek, S., Mikolajczyk, U., Szadkowska-Stanczyk, I. Dust Concentration Analysis in Non Coal Mining. Exposure evaluation based on measurements performed by occupational hygiene Laboratories in the years 2001-2005 in Poland. Medycyna Pracy, 62 (2), pp. 113-125, 2011.

[15] Bratveit, M., Moen, B.E., Mashalla, Y.J.S., Maalim, H. Dust exposure during small-scale mining in Tanzania: A pilot study. Annals of Occupational Hygiene, 47 (3), pp. 235-240, 2011.

[16] Kumar, C.H.K., Mallikarjuna, R.N., Singh, S.B.M. et al. Deterioration of pulmonary function in stone quarry workers Biomedical Research-India, 25(2), pp. 261-266, 2014.

[17] Alfaro Degan G., Lippiello D., Pinzari M. Valutazione sull'efficacia delle metodologie di contenimento dell'emissione di inquinanti aerodispersi in attività estrattive a cielo aperto: un caso di studio nel comparto laziale. GEAM. Geoingegneria ambientale e mineraria, 139 (2), pp. 5-12, 2013.

[18] Bluvshtein, N., Mahrer, Y., Sandler, A. Evaluating the impact of a limestone quarry on suspended and accumulated dust. Atmospheric Environment, 45 (9), pp. 1732-1739, 2011.

[19] Alfaro Degan G., Lippiello D., Pinzari M. A geostatistical approach to the functional analysis space technique: a case of study. Advances in Safety and Reliability - Proceedings of $16^{\text {th }}$ European Safety and Reliability Conference (ESREL). Ed: Kolowrocki K, Taylor \& Francis, Vol. 1, pp. 45-52, 2005.

[20] Patrucco, M.. Sicurezza ed ambiente di lavoro. Particolati aerodispersi, Politeko, Torino, 2003.

[21] Madungwe, E., Mukonzvi, T.,. Assessment of Distribution and Composition of Quarry Mine Dust: Case of Pomona Stone Quarries, Harare. Atmospheric and Climate Sciences 2, pp. 52-59, 2011. 